\title{
Valor, Custo e Utilidade Marginal - Parte II
}

\author{
Eugen Von Böhm-Bawerk*
}

\begin{abstract}
Resumo: Neste artigo, de importância fundamental para a compreensão do posicionamento histórico dos economistas austríacos com respeito à relação entre valor, custo e utilidade marginal, o autor responde a críticas elaboradas por Heinrich Dietzel contra os teóricos do valor marginal. O autor também discute a situação científica da teoria do valor no final do século XIX.
\end{abstract}

Palavras-Chave: Economia Austríaca, Teoria do Valor Marginal.

\section{Value, Cost, and Marginal Utility}

\begin{abstract}
In this article of fundamental importance to the comprehension of the historical stance of the Austrian economists concerning the relationship between value, cost, and marginal utility, the author answers to the criticism elaborated by Heinrich Dietzel against the theorists of the marginal value. The author also discusses the scientific status of the theory of value at the end of the $19^{\text {th }}$ century.
\end{abstract}

Keywords: Austrian Economics, Marginal Value Theory.

Classificação JEL: B53, B519.

\footnotetext{
* O presente artigo apareceu originalmente nos anuários de Conrd, Jahrbücher für Nationalökonomie und Statistik, Dritte Folge, Dritter Band (Jena: Verlag von Gustav Fischer, 1892), p. 321-367. O texto original em alemão foi traduzido para o inglês por Georg Reisman. Os números em colchetes referem-se à paginação no texto original. A primeira parte do trabalho foi publicada na edição anterior e a terceira e última parte será publicada na próxima edição do periódico MISES: Revista Interdisciplinar de Filosofia, Direito e Economia.

Traduzido da versão em inglês para o português por Ligia Maria Filgueiras.
}

\footnotetext{
"** Eugen von Böhm-Bawerk nasceu em 12 de fevereiro de 1851 na cidade de Brno, na região da Morávia, no Império Austro-Húngaro. Estudou direito na Universidade de Viena, por onde se formou no ano de 1872. Trabalhou entre os anos de 1872 e 1880 no Ministério das Finanças do Império Austro-Húngaro, no qual ocupou diversos cargos. Lecionou na Universidade de Innsbruck entre 1881 e 1888, e na Universidade de Viena em 1880 e de 1904 a 1914. Foi embaixador austríaco na Alemanha em 1897. Ocupou, em três ocasiões distintas, o cargo de ministro das finanças, sendo o titular da pasta em 1895, de 1897 a 1898 e de 1900 a 1904. É autor da obra monumental Kapital und Kapitalzins [Capital e Juros], publicada em três volumes, respectivamente, em 1884, 1889 e 1909. Em língua portuguesa, dentre seus inúmeros trabalhos, encontra-se disponível apenas o livro A Teoria da Exploração do Socialismo Comunismo (Instituto Ludwig von Mises Brasil, 2010). Faleceu no dia 27 de agosto de 1914 na cidade de Viena.
} 


\section{IV - Por QUE, RECONHECIDAMENTE, ESTIMATIVAS PRÁTICAS DE VALOR PODEM, MUITAS VEZES, TERMINAR COM UMA REFERÊNCIA A CUSTOS, NUNCA, ENTRETANTO, À EXPLICAÇÃO TEÓRICA \\ DESSAS ESTIMATIVAS}

Na prática, terminamos inúmeras vezes com uma valoração baseada em custos. Se alguém me perguntar que valor dou a um agasalho de inverno que posso comprar, a qualquer momento, a um custo de 40 florins, responderei sem hesitação e sem mais considerações: 40 florins. Se fosse custar apenas 35 florins, então decidiria muito rapidamente e responderia resolutamente: 35 florins. Deste fato indiscutível, Heinrich Dietzel (1857-1935) aparentemente deu a impressão que a explicação dos teóricos do valor marginal que, mesmo nesses casos, retoma alguma utilidade marginal, não é nem natural, nem fiel à natureza, mas faz "terríveis" desvios por meio de um verdadeiramente supérfluo "jeu d'esprit spirituel". Que justificativa tem esta impressão?

Não tem nenhuma justificativa. Decorre de uma confusão entre aquilo que os indivíduos fazem ou têm de fazer se quiserem estimar o valor de um bem na prática, e aquilo que a ciência tem de fazer se quiser explicar as valorações práticas em si.

$\mathrm{O}$ fato de que, sob certas condições que ocorrem muito frequentemente, na prática valoramos os bens de acordo com seu custo, não apenas diretamente mas também em certo sentido "definitivamente" (isto é, não nos alongamos em pensar no assunto), está totalmente certo. Como já tive ocasião de mencionar acima, nós, teóricos do valor marginal, também não permitimos, de modo algum, que este fato nos escape, mas o reconhecemos com toda a clareza. [340] "Inúmeras vezes [...] medimos [...] o valor dos produtos simplesmente de acordo com seus custos" 1 .

\footnotetext{
${ }^{1}$ BÖHM-BAWERK, Eugen von. Grundzüge der Theorie des wirtschaftlichen Güterwerts. Nestes anuários. p. 71; compare, acima, p. 24 [329].
}

Mas quando e por que paramos com os custos em nossas estimativas práticas do valor? Quando já sabemos do nível dos custos com base em alguma causa ou fonte, ou os encontramos quando nos são dados através de circunstâncias externas. Então, precisamente, o nível dos custos forma aparentemente um ponto de apoio para nossas finalidades práticas, cujos fundamentos não necessitamos investigar a respeito. Acredito que não haja diferença de opinião entre mim e Dietzel a respeito da necessidade deste pré-requisito. "Inúmeras vezes", escrevi em lugar citado acima, "já sabemos o valor dos bens de custo, sem ter antes que desenvolvê-lo caso a caso, com base em seus fundamentos, e em todos estes casos" - continuei como citado acima "medimos o valor dos produtos simplesmente de acordo com seus custos, numa taquigrafia tão correta quanto expedita". Dietzel está cheio de declarações nas quais a presença da valoração baseada no custo é explicada por referências ao fato de que os custos de produção ou de aquisição em questão devem ser conhecidos por quem valora. Já apresentei acima toda uma coleção dessas observações, às quais faço referência aqui².

Nossas ponderações práticas a respeito do valor de um bem reprodutível terminam, portanto, com o "conhecimento" do nível de custo e, na verdade, com toda fundamentação. Entretanto, será que a ciência pode se permitir terminar sua explicação sobre o valor aqui? Certamente que não! Porque o nível dos custos, que é sinônimo do total dos valores dos bens de custo, é de fato, ele mesmo, um fenômeno de valor, portanto uma parte e, certamente, não a parte mais insignificante, daquilo que deve ser explicado. E esta explicação apropriada para a ciência não pode, de maneira alguma, ser suprida por meio do "conhecimento" das pessoas. Existe uma enorme diferença, em geral, entre o conhecimento de um fato como fato, e a explicação do fato. Todo fazendeiro sabe que, nos assim chamados "dias dos homens de gelo", em

\footnotetext{
${ }^{2}$ Veja, acima, p. 24, n. 25 [329, n. 2].
} 
maio, geadas noturnas e a reincidência do frio ocorrem frequentemente. Entretanto, dificilmente haverá alguém que considerará este conhecimento dos fazendeiros do fato como um fato, como equivalente à posse de uma explicação científica deste fato. E todo mundo achará mais do que estranho se os meteorologistas, embarcados numa explicação científica do fenômeno dos homens de gelo, viessem a anunciar que já não seria necessária nenhuma outra explicação, porque os fazendeiros já sabiam muito bem do fato sem isso!

Ora, uma diferença exatamente do mesmo tipo e tão grande quanto existe, por exemplo, entre o conhecimento de negociantes de cavalo de que um cavalo custa 150 florins em um determinado mercado e uma explicação [341] científica do nível deste preço. Ou entre o conhecimento de um produtor de que a fabricação de um determinado bem custa 18 florins, isto é, 12 dias de trabalho a 1 florin e 50 kreuzer por dia, e uma explicação científica de por que um dia de trabalho vale 1 florin e 50 kreuzer e, portanto, a quantia total equivale a 18 florins. O nível de preço ou de custo pode, em todo caso, ter o poder de um fato dado indubitável para as valorações práticas do indivíduo. Entretanto, para a tarefa explicativa da ciência, não é nada além de um fato que ainda não está explicado e, portanto, um fato que tem primeiro que ser explicado. Não é a solução do problema do valor, mas é, em si, uma parte deste problema, e certamente não a mais fácil.

$\mathrm{O}$ ato de valorar e o de explicar teoricamente as valorações são, portanto, em todo caso, duas coisas diferentes. Certamente não quero afirmar que Dietzel confundiu nitidamente estas duas coisas distintas, mas não deixou clara a diferença em seu pleno significado. E, com isso, está continuamente enganado por ideias e premissas que pertencem a uma área, para, de repente, e sem perceber, saltar para ideias e conclusões que pertencem a outra área. Suas polêmicas oferecem inúmeros exemplos disso. O exemplo mais frequente é dado por suas reiteradas polêmicas a respeito da urgência e da "finalidade" das valorações práticas com base no custo versus a superfluidade e repreensibilidade de "desvios" na explicação dessas valorações.

Uma hora este pensamento é até encoberto na forma de um princípio explícito, quando Dietzel diz "que, dado que a prática necessariamente impõe o uso do cálculo para o valor do custo tão logo quanto possível, a teoria deve, o mais diretamente possível, conduzir a isso" ${ }^{\prime 3}$.

Especialmente características a este respeito, entretanto, são as numerosas observações de Dietzel referentes à aplicação dos "custos" como padrão de valoração. Dietzel não se cansa de enaltecer as vantagens especiais que os custos indicam como padrão de valoração em comparação com a utilidade marginal. O padrão do custo é "mais conveniente", "mais preciso", "mais exato", "mais completo". Em comparação com uma vaga valoração flutuante de acordo com a utilidade marginal, a valoração de acordo com o custo significa "um enorme avanço". As utilidades concretas que os bens fornecem só são comensuráveis com dificuldade; as quantidades de trabalho ou de custo que serão necessárias para sua reprodução são facilmente comensuráveis ${ }^{4}$, e assim por diante.

Haveria pouco ou nada a se opor contra isto se Dietzel não oferecesse sempre essas glorificações do padrão custo em um tom polêmico contra os teóricos do valor marginal e as combinasse com a insinuação de que a teoria da utilidade marginal [342] de alguma forma pretende depor esse excelente padrão para "negar-lhe" seu próprio "domínio" e "pôr no lugar" o "mais insatisfatório e inferior método" de valoração de acordo com a utilidade marginal, até mesmo para a categoria de bens reprodutíveis, para a qual o método mais satisfatório de valoração de custo há tempos já existe $^{5}$. Ou seja, Dietzel apresenta o assunto como se no espírito de nossa teoria as pessoas tivessem que aplicar o método insatisfatório

\footnotetext{
${ }^{3}$ Wert- und Preistheorie, p. 689.

${ }^{4}$ Werttheorie, p. 595; da mesma forma, muitas vezes.

${ }^{5}$ Werttheorie, p.606
} 
da valoração marginal até mesmo com relação aos bens reprodutíveis, ao invés do método conveniente e exato de acordo com o custo.

Este é um grande equívoco a respeito da nossa visão que, por sua vez, está enraizado no fato de que Dietzel confunde duas coisas que nós, teóricos do valor marginal, tomamos o cuidado exatamente para que não haja confusão: a saber, a realização da valoração prática e a explicação teórica dessa valoração. Não temos a intenção de reivindicar qualquer margem menor para a aplicação prática do exato padrão custo do que Dietzel. Onde quer que as pessoas já saibam o total do custo - e onde elas não o saibam, dificilmente continuam a usar a valoração do custo mesmo que seja de acordo com Dietzel - então, de acordo com nosso modo de ver, também elas simplesmente aplicam o certamente mais conveniente e mais exato padrão custo sem torturar o cérebro a respeito de uma nova derivação do valor dos próprios bens de custo a partir de qualquer utilidade marginal. Entretanto, para que o total do custo lhes seja conhecido em termos de um número de valor definido, primeiramente tem que ser fixado em um determinado nível, através de outras forças e ocorrências - que, em sua maior parte, são de natureza socioeconômica. E, naturalmente, não é encargo menor da ciência fornecer a explicação desse novo ramo da formação do valor que vai além do campo de visão limitado do indivíduo, como a explicação do ramo que se encontra dentro deste campo de visão. Quando a teoria continua a explicação do valor dos bens de custo, então, de fato, ela chega, em última análise, à utilidade marginal como a causa.

A inadequação da explicação teórica com base no custo ou na dificuldade de aquisição parece particularmente importante, creio eu, quando se concebe - prática contra a qual não tenho nenhuma obje- ção em si -, como Scharling ${ }^{6}$ e Dietzel7, não apenas os custos reais de produção, mas também os custos de aquisição por meio da troca como um fenômeno de custo. Estes "custos de compra" formam diretamente a base - desde que já sejam conhecidos - para a valoração subjetiva do artigo pelas pessoas individuais que têm a ver com este artigo, [343] e Dietzel ${ }^{8}$ se atribui uma tarefa muito supérflua quando acredita que tem primeiro que provar isso contra mim.

No entanto, parece-me claro como água, primeiro, que neste caso o nível do custo de aquisição, ou seja, o nível do preço de mercado, requer em si uma explicação mais detalhada e, segundo, que nesta explicação do nível do preço não se pode recorrer a essas valorações de custo pelos indivíduos se não se quiser tornar-se culpado de uma enorme circularidade. Por que as pessoas estimam o preço de um agasalho de inverno em 40 florins? Porque ele "custa" isso no mercado. E por que ele custa isso no mercado? E quem quer que queira, aqui, responder outra vez, simplesmente, "porque as pessoas estimam o abrigo de inverno em 40 florins" e, ao fazê-lo, tenha em mente as mesmas valorações que se baseiam no "custo de aquisição" de 40 florins, não estaria dizendo nada mais que: o agasalho de inverno custa 40 florins porque custa 40 florins! Ou explicaria o surgimento do preço com base no que o preço veio a ser.

Naturalmente, o próprio Dietzel é suficientemente sagaz para ver essa circularidade de raciocínio absolutamente óbvia por aquilo que é, e evitá-la. Só é capaz de fazê-lo, entretanto, ao preço de que, justo no ponto mais decisivo, ele deixa de dar suporte à sua teoria do custo.

\footnotetext{
${ }^{6}$ Werttheorie und Wertgesetz, nos presentes anuários, nova série, vol. 16, pp. 417 ss., em seguida 513ss., passim.

7 "No caso de mercadorias compráveis à vontade, o custo que estabelece o padrão para a valoração subjetiva daqueles dispostos a comprar tem por base o total de dinheiro a ser gasto na compra" (Wert- und Preistheorie, p. 691).

${ }^{8}$ Werttheorie, p. 602s.
} 
Vale a pena o esforço de se acompanhar mais detalhadamente, de alguma forma, a linha de pensamento de Dietzel, que não se dá sem estranhas voltas e reviravoltas. Dietzel concorda conosco, teóricos do valor marginal, quanto ao fato de que se deve primeiro explicar os preços de mercado com base nas valorações subjetivas dos bens pelos indivíduos no mercado 9 . Ora, deve-se esperar que Dietzel que, por outro lado, adora apresentar sempre os custos com tamanha ênfase como a base decisiva de valorações, afirmaria também aqui que as valorações subjetivas dos indivíduos no mercado são simplesmente valorações de custo. Entretanto, de modo algum o faz. Ao invés disso, primeiramente descobre que é necessário fazer uma distinção entre os compradores e os vendedores. As valorações decisivas dos primeiros são, em geral, baseadas não nos custos, mas na utilidade - "valorações de utilidade" ${ }^{\prime 10}$. As valorações dos vendedores, no entanto, são baseadas, de fato, "diretamente" nos custos de produção. Entretanto, "uma vez que o bem a ser trocado tenha sido trazido ao mercado, a valoração da utilidade toma o lugar da valoração do custo (mesmo no caso deles) enquanto durar a transação de mercado" 11.

Deve-se observar com cuidado o que significa isso. Significa, em outras palavras: na hora da decisão, na hora em que a valoração tem que ter uma importância realmente prática para a ação, todos as partes, compradores e vendedores, até mesmo de acordo com Dietzel, põem suas valorações de custo, enaltecidas como infinitamente práticas, [344] de lado e se permitem serem guiadas exclusivamente por valorações de utilidade, as valorações tão desprezadas por Dietzel como inexatas, insatisfatórias, e de modo algum capazes de uma real mensuração! Só depois que tudo foi decidido, quando o pre-

\footnotetext{
${ }^{9}$ Wert- und Preistheorie, p. 696

10 "Somente a valoração subjetiva do vendedor se baseia diretamente nos custos de produção, que a do comprador, por outro lado, na utilidade [...] esta valoração da utilidade (do comprador) é a direta" (Wert- und Preistheorie, p. 696).

${ }^{11}$ Idem. Ibidem, p. 698.
}

ço que surgiu resultante da interação das valorações de utilidade como um preço feito que já é "conhecido", as pessoas tornam a desenterrar a valoração do custo que foi antes cuidadosamente posta de lado e em relação à qual, em alguma medida, elas agora já não podem ser tomadas em sua palavra e permitir que ela "finalmente triunfe".

Diversos compradores aparecem no mercado querendo um determinado bem permutável. Cada um tem uma valoração de utilidade subjetiva do bem que difere da de todos os outros compradores. Esta valoração de utilidade é a valoração direta. Entretanto, assim que o preço pelo qual o bem está à venda, seu valor de custo objetivo, é conhecido, a valoração do custo finalmente triunfa ${ }^{12}$.

Quem não se lembra com isso do valente Falstaff, de como se fez cuidadosamente de morto durante a batalha, mas depois da batalha se vangloriou de seu triunfo sobre "Hotspur", morto por outra pessoa ${ }^{13}$. Ora, quantas quer que sejam as expressões e enfeites abstrusos que Dietzel venha a acrescentar aqui, um fato, ainda assim, não pode ser ocultado: a saber, o de que, na explicação da formação de preços, o próprio Dietzel não pode usar as valorações de custo dos compradores em potencial que se baseiam no "total de dinheiro a ser definido na compra", e é forçado a cair de volta nas valorações de utilidade. Entretanto, é exatamente este o ponto do qual tudo em nossa controvérsia depende porque, de fato, foi na realidade por sua causa que Dietzel se envolveu em toda essa controvérsia. Pois o que distingue a nossa teoria, a teoria da utilidade marginal, da habitual teoria do custo é, na verdade, no fundo, a simples proposição que, na verdade, é decisiva, a de que, para nós, a explicação do valor com base nos custos não é uma explicação final, mas que o "nível de custo" - seja ele o de "custos de produção" reais ou "custos de aquisição" se apresentan-

${ }^{12}$ Wert- und Preistheorie, p. 696

13 Isso parece ser uma referência à peça de William Shakespeare (1564-1616) Henrique $V$, parte 1, ato 5, cena 4. (N. T.) 
do no preço de mercado - constitui, em si, um fenômeno de valor que necessita de explicação. E essa explicação torna necessário retornar a uma valoração inicial de acordo com a utilidade, ou a utilidade marginal.

Nossa opinião, portanto, para voltarmos ao que foi dito anteriormente, não é, de maneira alguma, que as pessoas que valoram bens reprodutíveis irão sempre, ou mesmo na maioria das vezes, valorá-los de acordo com a utilidade marginal ao invés de ser de acordo com o custo. Antes, nossa opinião é que, ocorrendo realmente as valorações de custo, para que sejam possíveis, pressupõem a existência de outras valorações precedentes. Estas valorações anteriores procedem tanto das mesmas pessoas quanto, com mais frequência, de outras pessoas; referem-se, em sua maior parte, a outros bens (os bens de custo); e são realizadas de acordo com a extensão da utilidade marginal. E, finalmente, nossa opinião é que [345] essas outras valorações, feitas de acordo com a utilidade marginal, devem ser incorporadas no campo da explicação científica, se a ciência deve explicar todo o fenômeno da formação de valor e não uma parte fora de contexto.

Em geral, digo eu, essas outras valorações procedem de outras pessoas que não as que valoram diretamente os bens reprodutíveis de acordo com seus custos. Este é sempre o caso, por exemplo, quando nossa valoração de custo é baseada em um preço de compra. Quando um empregador valora seus bens que lhe custaram 12 dias de trabalho em 18 florins, ou seja, o salário de 12 dias a 1 1/2 florin por dia, um grande número de valorações por parte dos produtores, e um número ainda maior de valorações por parte dos consumidores, tiveram seu papel na determinação do valor de um dia de trabalho em 1 1 1/2 florin, como já expliquei, mais detalhadamente, em meu

Positive Theorie des Kapitales ${ }^{14}$.

Um Robinson Crusoé, por outro lado, irá também sempre, é claro, tomar a valoração de acordo com o custo, que provém da

${ }^{14}$ P. 236 ss. [A tradução inglesa aparece em BÖHMBAWERK, Capital and Interest, vol. 2, p. 249ss.] valoração dos bens de custo que, por sua vez, conduz, finalmente, a uma ou outra utilidade marginal, ou seja, a uma valoração que ele próprio deve ter feito numa ocasião anterior e da qual ele ainda "sabe". Em todo o caso, me parece que Dietzel não tem uma visão completa adequada a respeito do modo pelo qual esta conclusão "econômica interior" da valoração do custo ocorre. Uma vez que Dietzel, neste ponto da explicação da formação do valor $^{15}$, põe ênfase especial no caso de Robinson Crusoé e me pede expressamente que aplique minha crítica a ele, devo dizer algumas palavras sobre o assunto.

\section{V - ObSERVAÇÕes A RESPEITO DE Robinson Crusó́ e a Respeito DE CAPRICHOS}

Dietzel permite que seu Robinson ${ }^{16}$ projete uma escala de valor dos bens reprodutíveis em sua posse por meio do seu trabalho.

Se sua cabana é reproduzível em 10 horas, sua rede também em 10 horas, seu arco em 8 horas, e seu suprimento de alimentos em 5 horas, "então Robinson, se ele entende de algum modo como calcular economicamente, calculará o valor destes bens com os números $10,10,8,5$ ". Estou de pleno acordo!

Como Dietzel consegue que Robinson chegue a este cálculo? Robinson deve dizer para si mesmo que, se ele já não tivesse a cabana, ou se fosse perdê-la, por exemplo, por causa de um incêndio, teria que empregar 10 horas de seu tempo de trabalho na construção dela e, evidentemente, teria que tirar as mesmas 10 horas de trabalho da produção de outros bens úteis que ele poderia, não fosse esse o caso, produzir. Da posse de sua cabana, portanto, depende efetivamente "o total da satisfação da necessidade", que seria o resultado do [346] emprego de 10 horas de trabalho voltadas para a produção de outros

\footnotetext{
${ }^{15}$ Wert- und Preistheorie, p. 685s., 706.

${ }^{16}$ Werttheorie, p. 584 ss.
} 
bens úteis. Por outro lado, é claro, da posse do suprimento de alimentos, que é reproduzível em 5 horas, depende inteiramente, do mesmo modo, o benefício de apenas metade da quantidade de outros bens úteis, ou seja, de tantos bens úteis quanto Robinson poderia de outra forma produzir em cinco horas de trabalho. Robinson deve, portanto, dizer a si mesmo: "se eu perder a primeira (a cabana), eu perco o dobro da quantidade de satisfação de necessidade do que se eu perder a última (a comida)".

Esta afirmação também está absolutamente correta e ainda, totalmente no espírito da teoria da utilidade marginal. Porque a quantidade de satisfação de necessidade que depende do trabalho em si através da intermediação de outros bens úteis a serem produzidos por meio dele, representa, de fato, como o próprio Dietzel também o manifesta repetidamente ${ }^{17}$ - nada mais do que a utilidade marginal do trabalho.

Agora, entretanto, Dietzel coloca uma nuance interessante pela qual ele mostra claramente querer evitar a última das consequências da teoria da utilidade marginal que considera desagradável - a valoração de acordo com as intensidades do sentimento. Ou seja, Robinson Crusoé, de fato, pode deixar claro para si mesmo - Dietzel acredita que necessidades concretas satisfaria através de uma aplicação alternativa das 10 e 5 horas do trabalho em questão. Neste caso, uma valoração plenamente informada, de acordo com a utilidade ou utilidade marginal, estaria presente. Entretanto, ele não precisa tornar isso absolutamente claro. Ele também pode calcular abstratamente, "com quantidades de bens dos produtores universais, o valor de compra original, o trabalho", que é "a causa abstrata daquela (dependente) satisfação de necessidade futura". Ele pode, eventualmente, raciocinar do seguinte modo: se a cabana é reproduzível em 10 horas e o suprimento de comida em 5 horas, a presença da primeira me poupa o dobro da quantidade do trabalho

\footnotetext{
${ }^{17}$ Idem. Ibidem, p. 594-595.
}

útil abstrato do que com a presença da última, com o resultado de que o dobro da quantidade de satisfação de desejo depende da presença da primeira, bem como da presença da última. Portanto, o valor da cabana tem que ser exatamente duas vezes o valor da comida.

Aqui, há uma tentativa muito engenhosa, aparentemente, de se eliminar do cálculo do valor, que não pode evitar a referência à utilidade marginal, no mínimo a determinação da utilidade marginal. A utilidade marginal é, por assim dizer, trazida para o cálculo como um x que não é depois calculado. Mesmo que eu não saiba, ou não queira ter o trabalho, de determinar o valor de $x$, ainda assim é certo que $2 x$ é o dobro de $x$ e que $4 x$ é também o dobro de $2 x$. E, onde quer que tal conhecimento seja suficiente, a determinação de x é, de fato, dispensável.

Onde quer que tal conhecimento seja suficiente. Este é o ponto onde a crítica da construção de Dietzel tem que começar. Ou seja, não se deve perder de vista o fato de que, pelo método [347] descrito por Dietzel, não se chega de modo algum a uma valoração real, ou seja, à formação de um juízo a respeito do tamanho da importância dos bens comparados para o bem-estar. Aprende-se, de fato, que a cabana vale duas vezes o suprimento de comida para o bem-estar. Mas não se aprende a respeito de qualquer desses bens, que são supostamente "valorados" de acordo com seu valor, se eles valem realmente muito ou pouco e, menos ainda, o quanto eles valem para o nosso bem-estar. É exatamente como se duas peças de pano ou de lona, de comprimentos desconhecidos, tivessem que ser medidas meramente uma em comparação com a outra, e o resultado daí obtido é que uma peça vem a ser exatamente uma vez e meia o comprimento da outra. Nesse caso, se não se investigar, realmente, nada mais, e não se souber nada além disso, o comprimento absoluto das duas peças pode muito bem ser de $1 / 2$ e $3 / 4$ de metro, ou 4 e 6 metros, ou 20 e 30 metros.

Ora, há certamente finalidades particulares para as quais até mesmo o conhecimento tão limitado e imperfeito pode ser 
suficiente. E entre estas finalidades estaria a construção da escala comparativa, enfatizada por Dietzel em suas discussões, entre todos os bens reprodutíveis em posse de Robinson Crusoé. Entretanto - e isto, parece-me, Dietzel não tornou suficientemente claro para ele mesmo - tal escala é em si de muito pouco uso na prática econômica. Ela só pode ser aplicada se as circunstâncias nas quais uma decisão econômica a ser feita forem tais que somente a escolha entre dois bens reprodutíveis é envolvida, nada mais, seja lá o que for. Raramente, entretanto, constituem-se assim as circunstâncias práticas, especialmente para um Robinson Crusoé que carece totalmente da oportunidade mais frequente para a comparação de dois bens - a troca. A escala falha assim que, por exemplo, Robinson Crusoé tem que comparar um bem reprodutível com um bem que não é reprodutível, por exemplo, sua cabana com o único agasalho europeu em sua ilha que ele conseguiu salvar. Em tal caso, Robinson Crusoé tem que valorar ambos os bens de acordo com a utilidade marginal, não apenas o agasalho, que não é reprodutível, mas também a cabana, que é reprodutível. Esta é uma coisa da qual Dietzel parece não se dar conta, ou não o suficiente. Porque o que se requer para a comparação do valor de dois bens, como Dietzel uma vez observou muito corretamente, é um "denominador comum". Aqui, o trabalho já não pode mais ser este denominador comum. Ao contrário, para que possa comparar a cabana com o agasalho, sendo este último obrigado, sem dúvida, a ser valorado de acordo com a utilidade marginal ${ }^{18}$, [348] Robinson Crusoé tem, obviamente,

\footnotetext{
18 Dietzel, na verdade, deixou claro que nunca, em momento algum, duvidou da exatidão da teoria da utilidade marginal para bens escassos. No entanto, apesar disso, aproveitou a ocasião acima (Werttheorie, p. 584 s.) para fazer algumas observações um tanto irônicas sobre o embaraço em que Robinson iria se encontrar se, "jurando sobre as palavras dos mestres da utilidade marginal", quisesse valorar o agasalho de acordo com a utilidade marginal. Porque, por exemplo, como ele poderia imaginar a última das satisfações da vontade ou a utilidade marginal assegurada, por outro lado, por meio do agasalho?
}

que primeiro valorar a cabana de acordo com a utilidade marginal. Ou seja, ele tem que ir além da valoração de acordo com os custos ou com horas de trabalho abstratas por meio do cálculo de $x$, recorrendo à utilidade marginal do próprio trabalho. Este complemento, observe-se, não será nem particularmente difícil nem particularmente complicado. Pelo contrário, Robinson provavelmente vai descobrir sua avaliação definitiva sobre a importância absoluta do que ele pode fazer para o seu bem-estar com a unidade de seu dinheiro de compra, a hora de trabalho ou o dia de trabalho, tão rápido quanto nós, seres sociais, fizemos há muito tempo, de uma vez por todas, com a unidade monetária - o florin, o marco, a coroa, o penny. Nas ocasiões práticas individuais, nas quais, então, voltamo-nos para os marcos, pennys ou horas/homem em nossos cálculos de valor, nós já "sabemos" o valor dessas unidades e não precisamos mais derivá-lo da utilidade marginal caso a caso. Entretanto, por essa razão, não é menos verdade que todas essas valorações estão fundamentadas numa valoração realizada, na prática, de acordo com a utilidade marginal, hoje ou muito tempo atrás.

Não menos insuficiente, por outro lado, é a valoração não especificada de acordo com a "utilidade abstrata" nos numerosos casos em que Robinson tem que comparar um bem não com outro, mas com necessidades, por exemplo, quando se trata de uma escolha econômica consumir um bem reprodutível para uma finalidade específica. Vamos imaginar que Robinson fez uma quantidade de flechas gastando duas horas de trabalho e gostaria alegremente de atirá-las, por divertimento ou para a prática de tiro ao alvo, ou em passarinhos voando por perto. Ele pode se permitir tal uso delas?

A resposta a esta pergunta será obviamente muito diferente dependendo de se a utilidade marginal de duas horas de trabalho conta muito ou conta pouco. Se conta muito, se, por exemplo, nos primeiros dias após chegar à sua ilha, Robinson tem primeiro que tomar as providências mais necessárias, das 
quais teria que abrir mão se dedicasse seu tempo à prática do arco e flecha. Não é uma questão de satisfação da "última" vontade ou de utilidade marginal, mas simplesmente uma questão de importância da vontade dependente, ou seja, da necessidade de roupas ou da "utilidade" do agasalho. Se Dietzel tivesse se familiarizado com a teoria da utilidade marginal, [348] poderia ter-se poupado desta polêmica também, assim como de outras tantas. Porque os teóricos do valor marginal explicaram com toda a clareza desejável e detalhadamente que, em casos de exemplares únicos, a utilidade marginal é idêntica à utilidade desses exemplares únicos ${ }^{19} \mathrm{e}$ que, no caso de bens duráveis, tais como o agasalho, a utilidade dependente ou utilidade marginal compreende não apenas uma satisfação de vontade, mas toda uma série delas ${ }^{20}$. De acordo com nossa teoria também, Robinson não tem, portanto, apenas uma única satisfação de vontade a considerar, mas, sim, toda a utilidade do agasalho. Afinal - uma coisa que Dietzel parece ter deixado passar completamente, ainda que os teóricos do valor marginal tenham declarado muito claramente ${ }^{21}$ - a proposição principal da teoria deles é que o valor dos bens é determinado pela importância das vontades dependentes deles. O conceito e nome utilidade marginal entrou em ação apenas na explicação mais precisa de qual, entre diversas vontades em consideração, é a vontade dependente que se procura atender. Naturalmente, esta explicação mais precisa não é necessária quando somente uma única vontade ou uma única série de vontades está em questão. [349] A resposta, naturalmente, será negativa. Por outro lado, será afirmativa, se Robinson já estiver preparado para todas as necessidades essenciais de modo que não

19 BÖHM-BAWERK. Grundzüge der Theorie des wirtschaftlichen Güterwerts. p. 31, 37.

${ }^{20}$ Idem. Ibidem, p. 33 s.

21 Por exemplo, Idem. Ibidem, p. 20 ss., Wieser, Ursprung und Häuptgesetze, p. 121ss., 126ss., Der natürliche Wert, p. 21, 23 ss. [Natural Value, op. cit., pp. 21 ss, pp. $24 \mathrm{ss}]$. tenha com que gastar duas horas disponíveis de trabalho que era mais urgente ou importante do que recorrer à prática do tiro.

É óbvio, portanto, que não se obteve nenhuma orientação utilizável com a valoração "abstrata" de custo, com a avaliação de que as flechas custam duas horas de trabalho. Só será utilizável no momento em que Robinson, por meio de uma nova decisão, perceber claramente quanto as duas horas de trabalho significam para ele em função das circunstâncias. Ou seja, quando completar a valoração do custo através de uma valoração positiva da utilidade marginal do trabalho empregado em um bem de custo.

Esse método de valoração que Dietzel acredita poder apresentar como característico não é, portanto, como se vê, característico, mas só pode ser aplicado em circunstâncias muito especiais, casuísticas, e em um número muito limitado de ocasiões: ou seja, quando se trata da comparação do valor entre vários bens reprodutíveis, um com o outro. Em todas as outras muito mais numerosas ocasiões da prática econômica de Robinson, até mesmo Robinson tem que voltar à utilidade marginal.

Ninguém sabe melhor do que os próprios teóricos do valor marginal ${ }^{22}$ que, como alega Dietzel ${ }^{23}$, pouca exatidão aritmética objetiva e muito capricho estão presentes na ponderação da utilidade marginal. Entretanto, o teórico não pode fazer a prática ser melhor do que é realmente. Ele não pode nem negar nem evitar o fato de que, em última análise, as pessoas fazem o que elas consideram proporcionar a "seu bem-estar" a estrela guia de suas ações econômicas. E ele pode tampouco impedir ou negar que as pessoas, de acordo com sua inclinação e humor, muitas vezes consideram coisas muito estranhas próprias a proporcionar "seu bem-estar". Tais aberrações caprichosas de paixão, de indulgência cega, de negligência, de fraqueza de vontade, são realmente a fonte de onde fluem

\footnotetext{
${ }^{22}$ Ver, por exemplo, meu Grundzüge der Theorie des wirtschaftlichen Güterwerts, p. 50s.

${ }^{23}$ Werttheorie, p. 585.
} 
milhares e milhares de ações tolas e antieconômicas, que toda vez são desencadeadas por valorações igualmente tolas e imaturas com relação a meios e fins. Se, no entanto, como é absolutamente inegável, o poder de impressões subjetivas e muitas vezes de caprichos é um elemento da prática econômica, então também tem que ser um elemento de uma teoria que seja realmente fiel aos fatos. Como afirmei em outra ocasião: Um cálculo correto, um cálculo inexato, um cálculo falso de um ganho de bem-estar conduz, respectivamente, a uma valoração correta, inexata, ou a uma falsa valoração, como, aliás, inúmeras delas aparecem na vida econômica. O cálculo falso, no entanto, serve tanto [350] na explicação correta da falsa valoração quanto os cálculos corretos servem na explicação correta de valorações corretas.

Pergunto, além disso - e aqui vamos deixar Robinson e voltar à nossa moderna economia - de onde se originam os números exatos do custo que propiciam a base de nossas valorações "perfeitas" e "exatas" de acordo com o custo? Elas mesmas não são nada mais que resultado de "caprichos"! O próprio Dietzel, de fato, entende sua lei dos custos de um modo que os custos mais altos gastos ao atenderem a uma determinada demanda são decisivos para o valor e o preçO ${ }^{24}$. Ora, o que decide que custos são os mais altos a serem gastos? Certamente, a condição de demanda! Se, por exemplo, 1 milhão de quintals de um bem podem ser produzidos a um custo de 10 florins por quintal, se um milhão e cem mil por apenas 10 florins 50 kreuzer por quintal, e já um milhão e duzentos mil por apenas 11 florins por quintal, assim o maior custo necessário totalizará 10 florins se, de fato, por um lado forem encontrados um milhão de compradores dispostos a pagar 10 florins por um quintal, e, por outro, não mais que um milhão de pessoas forem encontradas dispostas a pagar 10 florins 50 kreuzer. Se este último fosse o caso, o custo decisivo não seria de 10 florins, mas de 10 florins 50 kreu-

\footnotetext{
${ }^{24}$ Werttheorie, p. 592; Wert- und Preistheorie, p. 702ss.
}

zer. O valor dominante, portanto, dependeisto é claro e aceito-da situação de demanda. Por sua vez, entretanto, isto depende de que? Não há dúvida sobre isso também, e o próprio Dietzel afirma que isso depende da "valoração do uso" que o comprador dá ao bem, por um lado, e de seu dinheiro, por outro $^{25}$. Da mesma valoração do uso, portanto, da mesma "utilidade marginal" que, como Dietzel afirma em outro lugar ${ }^{26}$, sobe e desce de acordo com o "capricho" e a opinião, que "tem que passar por todas as dificuldades do sentimento", e que Dietzel considera ser um padrão tão ruim a ser utilizado que exclama com dúvida e ironia: “"Isso é realmente uma dosagem econômica de valor"?"

"Caprichos", portanto, não podem ser eliminados de nossas valorações; nem de nossas valorações "exatas" do custo. A diferença é apenas esta: onde nós valoramos diretamente de acordo com a utilidade marginal, baseamos nossa valoração em nossos próprios "caprichos." Onde valoramos "exatamente" de acordo com os custos, nós o baseamos nos caprichos de outras pessoas ${ }^{27}$; no resultado dos caprichos das centenas, milhares, ou milhões de compradores cuja demanda determina um valor de custo como o "mais alto necessário". Há que se admitir, imediatamente, que tal resultado dos caprichos é muito mais estável do que o capricho individual. De acordo com a "lei dos grandes números [351]", exatamente aqui uma série de desvios individuais opostos podem mutuamente compensar um ao outro, de modo que o resultado geral se altera pouco ou nada, embora tenha mudado muito para um indivíduo em particular ${ }^{28}$.

No entanto, eu gostaria de salientar algo que Dietzel novamente parece-me não ter considerado, ou não o suficiente: este tipo de determinação relativa de nossa base de valo-

\footnotetext{
${ }^{25}$ Wert- und Preistheorie, p. 699.

${ }^{26}$ Werttheorie, p. 595.

27 Exceto, naturalmente, nos casos de produção em casa, o que é raro hoje em dia.

${ }^{28}$ Wieser, Ursprung e Hauptgesetze, p. 160.
} 
ração não é característica de bens reprodutíveis, mas ocorre em uma ampla esfera, mesmo no caso de bens escassos. Ou seja, no caso dos bens escassos que, relativamente, em relação à demanda, são de fato escassos, mas, no entanto, certamente estão presentes em quantidade bastante grande e, portanto, possuem um mercado bastante extenso. Pedras preciosas de um tamanho e beleza incomuns, moedas antigas abundantes, selos, livros e afins têm um valor muito definido e sólido em seus respectivos "mercados", o que oferece ao indivíduo uma base tão precisa quanto sólida e exata para suas valorações, assim como o preço de mercado e o custo de produção fazem, por exemplo, por um chapéu ou um casaco reprodutíveis. Na verdade, até mais!

Mesmo em relação aos bens reprodutíveis em longo prazo, tais como grãos, álcool, café, lúpulo e assim por diante, nós realizamos nossas valorações, a maior parte chegando à exatidão dos centavos, não com base em custos de produção padronizados, mas com base em cotações de páginas financeiras dos preços de mercado momentâneos, sendo estes mesmos determinados, por sua vez, pela relação momentânea da "vontade" e da "cobertura" ou "oferta", cujo poder determinante Dietzel avalia tão baixo. Quando se vê, por exemplo, com que uniformidade e precisão todas as pessoas que lidam com o trigo - que, no intervalo entre duas colheitas, é um "bem temporariamente não mais reprodutível" valoram um quintal a 8 florins 55 kreuzer em uma determinada semana, nem mais nem menos, suscitam-se algumas dúvidas sobre a declaração de Dietzel de que a valoração de acordo com a utilidade ou a utilidade marginal, ou seja, a determinação do valor por meio da oferta e demanda com base nela, que é o único método aplicável para tais bens, é, em todos os casos, "o método menos exato de estimativa do valor econômico, que conduz apenas a resultados incertos" 29 .

Mas o que sucede de tudo isso? Sucede que, com qualquer opinião que Dietzel venha a acrescentar à sua polêmica contra valorações caprichosas de acordo com a utilidade marginal, não provará absolutamente nada contra a nossa teoria, ou mesmo a favor de sua teoria. Se for da opinião de que as valorações do custo estão inteiramente livres da influência dos caprichos, estará evidentemente errado. Porque, na determinação do "nível dos custos determinantes" - que não comentei aqui, mas que poderia facilmente comentar, na valoração dos próprios bens de custo originais -, caprichos e sentimentos [352] subjetivos são fatores decisivos. Se, no entanto, Dietzel se dá por satisfeito de salientar que, no caso de valoração de custo o indivíduo usa uma base diferente da de seu próprio sentimento subjetivo, tem toda a razão, mas, primeiro, não diz nada que os teóricos do valor marginal já não tenham dito e, segundo, não diz nada que seja exclusivo de bens reprodutíveis e justificasse um tratamento dualístico dos bens reprodutíveis e dos bens não reprodutíveis. Porque, como já foi explicado, tal base intermediária de valorações subjetivas que se pode obter por determinação numérica existe frequentemente também no caso de bens escassos. cos

${ }^{29}$ Werttheorie, p. 606. 